\title{
Humanização, Humanismos e Humanidades: PROBLEMATIZANDO CONCEITOS E PRÁTICAS NO CONTEXTO DA SAÚdE NO BRASIL
}

\author{
Dante Gallian, Universidade Federal de São Paulo (UNIFESP), Brasil \\ Luiz Felipe Ponde, Pontifícia Universidade Católica de São Paulo, Brasil \\ Rafael Ruiz, Universidade Federal de São Paulo, Brasil
}

\begin{abstract}
Resumo: $O$ presente artigo, resultado parcial do projeto de pesquisa em desenvolvimento intitulado "As Patologias da Modernidade e os Remédios das Humanidades: investigação e experimentação", financiado pela FAPESP, busca contextualizar a discussão sobre humanização em saúde, apontando os fundamentos histórico-filosóficos das modernas abordagens sobre o tema, problematizando as propostas de projetos e políticas de humanização. Propondo uma investigação "arqueológica» de certos conceitos chaves, este estudo procura identificar o "equivoco antropológico" de uma certa concepção de humanismo moderno, responsável pelo fenômeno patológico da desumanização e, por outro lado, intenta identificar na experiência das humanidades um caminho heterodoxo de formação humanistica e humanização na área da saúde. Para tanto, procura apresentar a proposta do Laboratório de Humanidades do Centro de História e Filosofia das Ciências da Saúde (CeHFi) da Escola Paulista de Medicina (EPM) da Universidade Federal de São Paulo (UNIFESP), fundamentado na leitura e discussão de clássicos da literatura universal, como um possivel caminho de formação humanistica e promoção de humanização na área da saúde.
\end{abstract}

Palavras Chave: humanismo, humanização, humanidades e saúde.

\begin{abstract}
This article, which is a partial result of the research project named "The Pathologies of Modernity and The Remedies of Humanities: investigation and experimentation", funded by FAPESP, aims to contextualise the discussion regarding humanisation in health, demonstrating the historical and philosophical basis of contemporary approaches of projects and policies of humanisation. Proposing an "archaeological» investigation of key concepts, this study aims to identify the "anthropological mistake» of a specific conception of modern humanism, responsible for the pathological phenomenon of dehumanisation. Moreover, this article tries to identify in the humanities experience a heterodox path of humanistic education and humanization in the health field. For this, the article aims to present the Laboratory of Humanities, activity of Center of History and Philosophy of Health Sciences (CeHFi) of Paulista Medical School (EPM) of Federal University of São Paulo (UNIFESP), Brazil, based on reading and discussion of classics of universal literature, as a way of humanistic education and humanization promotion in health field.
\end{abstract}

Keywords: humanism, humanization, humanities and health.

Revista Internacional de Humanidades Médicas

Volumen 1, Número 1, <http://tecnociencia-sociedad.com/revistas/>, ISSN 2254-5859

(C) Global Knowledge Academics y Fundación Iatrós. Dante Gallian, Luiz Felipe Ponde, Rafael Ruiz

Todos los Derechos Reservados. Permisos: soporte@gkacademics.com 


\section{A Era dos Extremos ${ }^{1}$}

$\mathrm{E}$ IS o Tí́tulo do último volume da trilogia — na verdade quadrilogia - escrita por Eric Hobsbawm (2005) sobre os «tempos modernos» que procura dar conta de analisar o contexto histórico do entre-guerras até o pós «queda do muro».

Chama atenção o fato de o eminente historiador inglês caracterizar também como dos «extremos» uma fase histórica que se inaugura justamente com o fim da polarização econômica, política e ideológica. Porém, o que se percebe é que, precisamente, o desaparecimento desta dimensão - mais que tudo retórica — do paradoxismo moderno acabou por revelar polarizações e extremismos muito mais reais e profundos.

Uma destas contradições ou extremos mais trágicos e patentes é, sem dúvida, o binômio do desenvolvimento técnico-científico versus desumanização. $\mathrm{O}$ avanço do conhecimento científico, aplicado prodigamente em realizações técnicas, transformou de forma radical e avassaladora, num tempo espantosamente curto, a realidade, o mundo em que vivemos e nos movemos: desde a sua dimensão "natural» —a paisagem, o clima, o ambiente - até a sua esfera "cultural» —a relação e a comunicação entre as pessoas, a família, a arte, o trabalho, etc-

Nesta «Era dos Extremos» em que vivemos, praticamente toda nossa existência está condicionada pela mediação científico-tecnológica, a qual determina, em grande medida, nossa maneira de ver, sentir, pensar, enfim, de ser. "Conhecemos", "sabemos», «vemos» - pelo menos do ponto de vista científico - muito mais do que se poderia imaginar em outros tempos a respeito do nosso planeta, do nosso universo e, de certa forma, de nós mesmos - principalmente no que concerne à nossa dimensão física, biológica- Desenvolvemos uma quantidade prodigiosa de recursos técnicos capazes de transformar radicalmente nosso ambiente, nosso corpo, chegando até à possibilidade de dispor, até certo ponto, da vida. Por outro lado, paradoxalmente, talvez nunca tenhamos chegado a tamanho grau de depredação, destruição e ameaça à natureza, gerando uma situação de grave crise ambiental, à qual corresponde também outra, não menos dramática, referente à vida humana em sua dimensão pessoal, ética e cultural. Concomitantemente aos efeitos da poluição e do esgotamento dos recursos naturais - $\mathrm{o}$ aquecimento global, dentre outros - convivemos com os efeitos da «cientificização» e "tecnificação» da vida e das relações humanas, que enfeixa uma série de patologias associadas à desumanização: a solidão, a depressão, o pânico, o desespero...

Em memorável ensaio intitulado A desumanização da arte (2005), o filósofo espanhol Ortega y Gasset, analisando a produção artística que se esboçava em princípios do século xx, sugere que a desumanização do homem moderno seria resultado de um afastamento radical da realidade da vida, na medida em que esta deixa de ser efetivamente uma realidade dada para passar a ser uma realidade a ser realizada. Neste sentido, a arte modernista, enquanto elegia das utopias modernas, corria o risco de subverter o papel histórico da obra de arte que seria o de fomentar a humanização, ou seja, promover o encontro do homem com os conteúdos mais profundos da sua própria humanidade, na tradução criativa da realidade.

Esse processo de afastamento radical da realidade humana, de alheamento, de esvaziamento, que identificava Ortega y Gasset ainda na aurora do modernismo, tor-

1 Texto inédito. Resultado parcial do Projeto Regular de Pesquisa "As Patologias da Modernidade e os Remédios das Humanidades: investigação e experimentação", financiado pela FAPESP (n. 2010/50448-0). 
nou-se, quase um século depois, uma marca registrada do chamado homem pós-moderno. O conhecimento, a aquisição do saber que, até pouco tempo atrás, encontrava-se unida de forma indissociável à formação pessoal, vai se tornando cada vez mais rapidamente mercadoria, produto a ser comercializado (Lyotard, 1998: pp. 4-5). O contemporâneo homem desumanizado caracteriza-se por funcionar numa freqüência frenética, cada vez mais acelerada, de produção e consumo. $O$ vácuo ou vazio de sentido, que se formou por força deste afastamento radical do conteúdo existencial, tem sido preenchido, ou mais bem disfarçado, por uma tecnologia cada vez mais sofisticada e complexa. Psicofármacos de última geração apresentam-se então como solução diante da ineficácia frustrante dos recursos tecnológicos multiestimulantes, que mesmo com a capacidade de criar realidades virtuais, não conseguem substituir com sucesso esta experiência a uma só vez dolorosa e vital da realidade da vida real.

\section{O DISCURSO DA HUMANIZAÇ̃̃o}

Diante disto, não é de surpreender que o alerta mais eloqüente e operativo tenha partido justamente do campo da Saúde. Não que os filósofos e humanistas já não viessem alertando e conclamando desde há muito sobre os perigos da desumanização - Ortega y Gasset é apenas um exemplo dentre muitos que vieram antes e depois dele- . Entretanto, sabemos por experiência (real, da vida) que é apenas quando a ameaça se torna doença e que começa a doer e a nos matar, que começamos efetivamente a nos preocupar e a querer reagir.

Assim, ainda que tenha aparecido em outras paragens e num tempo bem mais recuado, foi no território das "Ciências da Saúde» onde a idéia — hoje «bandeira»da humanização germinou com mais força (Souza, Mendes, 2009).

É fácil perceber hoje como é no campo da Medicina onde o impacto do desenvolvimento científico-tecnológico das últimas décadas se fez sentir com maior força. $\mathrm{O}$ avanço das pesquisas na área da fisiologia humana, da biologia celular e molecular, aliado às conquistas no âmbito da física, da química, farmacologia, assim como na descoberta e confecção de equipamentos sofisticados (que permitem explorar, sondar, escanear o interior do corpo, dos órgãos e das células) proporcionaram enormes transformações, não apenas na maneira de se praticar, mas também de se conceber a medicina. Atualmente, as Ciências Médicas ou Biomédicas figuram como a mais prestigiosa e recente esperança da Modernidade, chave para a resolução não só para todos os problemas e patologias que ela própria criou, como também e principalmente solução para o problema mais essencial de toda a história da humanidade: a superação da dor, do sofrimento e da própria morte.

É claro que a apoteose desta última e definitiva aventura do gênio humano teima em escapar quando tudo indica que já se está às portas - tal como nos casos, recentes, do Projeto Genoma, ou das pesquisas com células tronco (Gallian, 2005) — mas, por outro lado, os progressos alcançados em múltiplos âmbitos são inegáveis e evidentes. Basta lembrar o que se tem feito no campo terapêutico de doenças até bem pouco tempo consideradas incuráveis e letais. Mas eis que, paradoxalmente, é precisamente na vanguarda, na frente mais brilhante e promissora da Modernidade que a percepção do vazio e da sombra é sentida de maneira mais candente e dolorosa.

$\mathrm{O}$ atual atiçamento fervoroso da discussão sobre a humanização no âmbito médico — ou da saúde, para usar um termo mais abrangente- deve-se justamente à 
experiência radical do fenômeno da desumanização, em suas dimensões talvez mais profundas e alarmantes. Por um lado, isso advém, sem dúvida, da experiência vivida pelos profissionais da saúde, que se encontram, cotidianamente, com os exemplos mais eloqüentes das causas e sintomas da desumanização; por outro, da frustração dos doentes, desiludidos diante da incapacidade do aparato científico-tecnológico de lhes entregar o que prometeram. Sem esquecer, aliás, a "estocada» final neste contexto, desferida pela indiferença ou mesmo desprezo humano por parte dos profissionais que, na falência dos recursos técnicos, apresentam-se ainda mais ineptos no exercício das virtudes humanas. E isso - é mister dizê-lo - não por causa de uma especial maldade intrínseca aos médicos e profissionais da saúde em geral, mas pelo fato de que estes são tão vítimas desta patologia moderna — a desumanização — quanto os seus pacientes.

A percepção, a princípio difusa, dos efeitos da desumanização num contexto de crescente tecnologização e massificação fundamentou, no âmbito da saúde, a discussão sobre a necessidade da humanização (Cf. Martins, 2003; Deslandes, 2007). Inicialmente limitada à esfera acadêmica, há pouco mais de uma década o tema foi sendo introduzido em outros espaços, tendo alcançado inclusive dimensões legais e administrativas. Hoje, no Brasil, a humanização apresenta-se como objeto de leis e regulamentos governamentais (Brasil, 2003), como diretriz em programas curriculares de cursos superiores da área da saúde (Brasil, 2001) e como meta e diferencial em controles de qualidade de clínicas e hospitais. Uma quantidade considerável de estudos, publicações e material de caráter educacional vem sendo produzido e, em muitas instituições, é comum existir já grupos ou mesmo comissões oficiais de humanização. ${ }^{2}$

É ainda difícil avaliar o impacto de toda esta mobilização humanizadora nos diversos âmbitos da área da saúde. Os estudos referentes a estas ações recém começam a apontar os resultados (Cf. Neves, Massaro, 2009; Ceccim, Merhy, 2009). Entretanto, o que chama atenção em tudo isto é, de maneira geral, a ausência de fundamentos teóricos - históricos e filosóficos, principalmente- nos diversos discursos e "práticas» de humanização. Quase sempre, considera-se como óbvio que o que se entende por humanização seja o desenvolvimento de ações e atitudes que redundem numa melhoria das relações dos profissionais da saúde entre si e destes com seus pacientes, o que implica em maior respeito, consideração, atenção, enfim, uma maior humanidade. Neste sentido, programas de "treinamento» vêm sendo desenvolvidos, na intenção de promover «habilidades humanísticas» que serão «agregadas» às "competências técnicas» do profissional da saúde, seja na sua base educacional, seja no exercício de sua prática. Ao se analisar, entretanto, os resultados de tais abordagens ou programas, levando-se em consideração as opiniões e sentimentos dos que estão sendo treinados ou «educados», percebe-se claramente a sua ineficácia (Gallian, Reginato, 2009). Havendo perdido o élan com os fundamentos filosóficos e culturais humanísticos, essas novas propostas educacionais, nascidas no seio de uma cultura científico-tecnicista, pretendem «ensinar» ou «incutir» humanismo ou humanidade da mesma forma como ensina e incute habilidades cognitivas e técnicas (Gallian, 2002). Os educandos, por sua vez, encaram todo esse processo como mais um conjunto de conteúdos e técnicas que precisam ser incorporadas, num pacote de "competências» e "habilidades» já demasiadamente pesado e exigente, que, mais do que nada, incrementa a angústia e a ansiedade. Em suma, havendo descuidado o que é ser humano para além das competências e habilidades cog-

2 Para uma visão de conjunto acessar o portal Humaniza.org.br: http://www.portalhumaniza.org. br/ph/ (acesso em 29/10/09). 
nitivas e técnicas, a educação contemporânea, no intuito de humanizar, acaba, muitas vezes e paradoxalmente, por contribuir para a desumanização (Cf. Nakamoto, 2008).

\section{HuMANIDADES E HUMANISMOS}

Termo um tanto quando esquecido nas últimas décadas, associado frequentemente pelos cientistas sociais a uma visão conservadora e retrógrada do homem e da cultura, identificada com o "aprendizado moral e cívico que se fazia lendo os gregos e os latinos» (Ribeiro, 2001: p. 15), a palavra Humanidades, curiosamente, voltou a aparecer no vocabulário corrente dos meios acadêmicos e culturais do país. Sem estar ligado, ao que tudo indica, a qualquer escola ou movimento ideológico-intelectual determinado, este recente revival terminológico parece, ainda, para os seus usuários contemporâneos, não ter assumido contornos conceituais bem definidos.

É comum, hoje em dia, ver-se utilizar, algumas vezes, Humanidades como sinônimo de Ciências Humanas ou também como denominação de um campo de saberes alternativo ao universo das ciências e da tecnologia em geral. De qualquer forma, tal como acontece com o termo humanização, Humanidades vem sendo utilizado, no contexto atual, de forma mais intuitiva do que conceitual, apresentando um caráter muito mais potencial do que definidor.

Há pouco menos de uma década (2001) a proposta de criação de um novo curso de graduação na USP, intitulado "Humanidades", teria dado azo ao desenvolvimento de uma discussão que, sem dúvida, haveria de ser profícua e trazer desdobramentos interessantes. Entretanto, a não aprovação do projeto acabou por interromper o debate e, até certo ponto, o desenvolvimento da reflexão. De lá para cá pouco se avançou, em nosso meio, no sentido de uma discussão sobre o que se entende e o que se pretende com as Humanidades.

Historicamente, o termo humanidades deriva longinquamente do humanitas latino de Cícero e Quintiliano, que, segundo Delumeau (1984), se identificava com polidez de costumes e, mais especificamente, a civilização. No Renascimento, quando os intelectuais italianos, a partir de Petrarca, se voltaram novamente para os grandes escritores da Antiguidade, faziam no intuito de recuperar os valores da cultura que eles tinham exaltado. Esses intelectuais, a princípio estudiosos das línguas antigas - grego e hebraico, principalmente - começaram a ser identificados como humanistas. Muito rapidamente, entretanto, o humanismo passou a ser identificado como uma linha de pensamento, determinando o surgimento de uma nova escola filosófica, que logo se diversificou e caracterizou a forma de pensar na época moderna.

A princípio, como demonstra Eugenio Garin (1989), os humanistas do Renascimento transitaram indistintamente sobre os mais variados temas e objetos, militando seja no campo das artes, seja no das letras, ciências, filosofia e teologia. É apenas mais tarde, bem entrado já o século XVII, que vamos encontrar humanistas que começam a se especializar em certos campos do saber, dedicando-se, por exemplo, de forma mais específica às ciências, às letras ou às artes. Será, entretanto, apenas nos inícios do século XIX, quando do grande processo de reestruturação das universidades européias, que o termo humanidades iria aparecer para designar o conjunto de saberes e disciplinas que se arregimentavam fora do campo das ciências. Porém, num contexto de progressivo crescimento do prestígio da visão científica do mundo e do homem, as humanidades, enquanto "salvaguarda» de um "outro» saber, relacionado com a intuição e a tradição e não 
tanto com a razão e a experiência empírica, vão, rapidamente, como bem aponta Ortega y Gasset, em ensaio sobre $A$ Missão da Universidade (1999), desaparecendo do horizonte da educação, até reduzirem-se, nos currículos universitários, a disciplinas de «cultura geral», "último e triste resíduo de alguma coisa maior e mais importante» (idem: p. 60).

Paralelamente ao declínio das Humanidades, enquanto conjunto efetivo de saberes, no contexto acadêmico científico, assistir-se-á à emergência das chamadas Ciências Humanas e Sociais - retomada dos mesmos temas humanísticos, porém agora a partir de novas perspectivas teóricas e metodológicas, inspiradas ou simplesmente extraídas das Ciências Naturais e Exatas. Impulsionados e entusiasmados com o sucesso e conquistas dos novos métodos científicos no campo da física, química e biologia, muitos pensadores, a partir do século XIX, começarão a estudar e explicar o homem, sua cultura, sua história, seu comportamento social e moral, a partir de pressupostos empíricos e experimentais; muitas vezes tomando como base «descobertas» e «leis» das próprias Ciências Naturais. Nesse sentido, a perspectiva de abordagem associada às Humanidades foi, paulatinamente, perdendo prestígio enquanto conhecimento, já que seu fundamento não é científico — na acepção moderna do termo- - Num contexto em que conhecimento vai se identificando cada vez mais com pesquisa e investigação científica, as Humanidades identificam-se agora muito mais com exercícios e vôos da imaginação do que com saber efetivo, seguro, prático e socialmente útil. Na nova divisão hierárquica das práticas e saberes humanos imposta pela Modernidade, coube às Humanidades o "território da cultura», entendida aqui fundamentalmente como "entretenimento", "diversão", complemento ou verniz estético —útil apenas na medida em que pode ser transformado em mercadoria e ser consumido num mercado, cada vez mais ávido de compensações sensoriais, emocionais e oníricas-. Conhecimento prático e útil é fruto das Ciências; das Humanidades espera-se apenas devaneio ou reflexão, indispensáveis sem dúvida para a existência humana, porém num grau muito menos importante do que o conhecimento científico-tecnológico.

Por outro lado, cabe advertir também uma outra vertente de interpretação do Humanismo, de cunho mais filosófico, que, partindo também do renascimento, determinou, em grande parte, a construção da patológica visão de mundo moderna e que está relacionada à idéia de perfectibilidade. Dando fundamento antropológico às ciências modernas, este Novo Humanismo não deixou de colaborar de forma efetiva para o fenômeno desumanizador que caracteriza os tempos modernos.

Segundo autores como Emmanuel Faye (1998), Henri Gouhier (1987), John Passmore (2004) e Michael Oakeshott (1991), entre outros, sua característica é a noção de suficiência e autonomia da natureza humana, materializadas numa razão e vontade perfectíveis. Desdobra-se daí a ideia que a natureza humana contém em si todos os elementos necessários e suficientes para realizar sua vida em movimento de autoaperfeiçoamento contínuo e crescente (nos campos moral, político, técnico e epistêmico). Esta é a matriz do racionalismo (moda intelectual pós-renascentista, como diz Oakeshott) como a faculdade racional que tudo entende e tudo projeta, e seu produto suposto, a perfectibilidade. A pedra filosofal deste humanismo será identificada com a obra do filosofo italiano do final de século xv, Pico della Mirandola, Da Dignidade da Natureza Humana, e seu conceito de homem indefinido como oposto à ideia de desgraça e miséria presente na herança agostiniana medieval. ${ }^{3}$

3 Neste cenário, razão e vontade seriam limitadas por um a priori ontológico e teológico constituído ao redor do conceito de queda e pecado. 
Muitos foram os autores entre os séculos XVI e XVII (períodos mais característicos deste debate) que se opuseram, de uma forma ou de outra, ao humanismo filosófico, entre eles, Maquiavel, Montaigne, Pascal, Esprit, entre outros. O centro da disputa sempre foi — seja devido a um ceticismo de fundo ou a um agostinismo crítico mais pronunciado - se o homem apresenta mesmo características que sustentem a hipótese humanista no sentido de Pico della Mirandola e de outros autores concordantes. Nos séculos posteriores (até a atualidade), outros autores retomaram a questão em ambientes conceituais distintos (podemos perceber que a investigação revela uma clara migração do pólo teológico-filosófico e moral para o pólo filosófico-político, e mais recentemente uma retomada das angustias éticas e bioéticas).

A importância que ganhou a "tese da perfectibilidade» para o imaginário moderno foi tão grande (como uma espécie de mito fundador), que as críticas consistentes a ela feitas desde o século XVI não receberam a devida atenção enquanto críticas a perfectibilidade em si mesma. Assim, tal movimento termina por causar uma espécie de mentira antropológica de fundo: criticar a perfectibilidade significaria ferir a autoestima do ser humano, e por isso seria necessário calar sobre as hipóteses críticas que a filosofia (teologia e literatura) produziu desde então. Tal perspectiva se apropriou do conceito de humanismo, normatizando o seu uso e referenciando o discurso moderno da humanização.

\section{AS HUMANIDADES E A HUMANIZAC̣̃̃o}

O momento crítico em que nos encontramos, marcado fortemente, por um lado, pelo paradoxo do desenvolvimento científico-tecnológico versus desumanização e, consequentemente, pelo crescente ceticismo em relação às conquistas e realizações das ciências, e, por outro, pela crise dos fundamentos antropológicos da perfectibilidade, apresenta-se como contexto altamente propício para a retomada ou «resgate» das humanidades.

Efetivamente, a tecnificação do conhecimento e, consequentemente, da educação, tem fragilizado e comprometido, nas palavras de Janine Ribeiro, o próprio sistema, o próprio mercado. Num contexto de crescente dinamismo e diversificação, como é hoje, por exemplo, o mercado de trabalho, uma educação que vise apenas à eficácia técnica especializada, corre o risco de se tornar, paradoxalmente, obsoleta. Segundo o autor do projeto do curso de Humanidades, é uma educação fundamentada nelas que possibilitaria dar ao futuro profissional uma «base sólida», adequada para enfrentar os desafios desta realidade dinâmica e crítica em que vivemos.

Devemos preparar os alunos [escreve Janine Ribeiro] para uma vida de tempestades. E uma das melhores bússolas é o conhecimento dos clássicos —não porque eles dêem lições imortais, invariáveis, de moral, o que não tem cabimento ou sentido; mas porque, na sua diversidade, permitem exercitar o espírito com tal liberdade diante das injunções do cotidiano que, mudando este, a mente saiba encontrar um novo nicho, embora tão provisório quanto o anterior-. A idéia é portanto, que os clássicos, longe de ancorarem seus leitores na repetição das mesmas coisas, capacitem a lidar com as mudanças melhor do que um ensino apressado, o qual apostaria na espuma da impermanência. (Ribeiro, 2001: pp. 15-16). 
Num outro capítulo desta mesma obra que apresenta a proposta do curso de Humanidades, Teixeira Coelho retoma a questão enfocando o problema a partir do processo que ele denomina de "desculturalização do ensino» (Coelho, 2001). Entendendo a "experiência da cultura» — ao qual ambos autores identificam com as artes, literatura e filosofia, "a cujo conjunto chamamos de humanidades» (Ribeiro, 1991: p. 17) - como meio facilitador da "experiência do difuso e do indeterminado» e da "ampliação da esfera de presença do ser», a educação através das humanidades apresenta-se como elemento indispensável para a própria sobrevivência da universidade no século XxI. Na visão de Teixeira Coelho, é através do exercício das humanidades que se desenvolve o cogito prismático, o tipo de pensamento requerido para abordar a realidade humana de uma "maneira não idealista», portanto livre das condicionantes da "precisão e do significado", tão característicos da perspectiva científica moderna. A visão prismática da realidade — aquela propiciada pela arte, pela literatura - ${ }^{4}$ possibilita transcender uma interpretação do «mundo e da vida de acordo com o metro do preciso e do significado, do certo e do errado, do correto e do falso» (Coelho, 1991: p. 69).

Aqui [aponta o autor, ao comentar um conto de Tchecov] interessa ver como um dado conto, uma certa peça de literatura, de ficção, de arte, lida com a indeterminação e a difusão, e como a leitura de um conto assim é uma experiência da indeterminação que permite ao leitor, na descrição de F. R. Leavis (...), "uma renovação de [sua] vida sensual e emocional e a aquisição de uma nova consciencia». (Idem: p. 72).

Pouco menos de um século atrás, o médico (endocrinologista) e humanista Gregorio Marañón, ao fazer a crítica da perspectiva cientificista que se afirmava com toda força —e à qual ele chamava de medicina dogmática - já apontava para o valor fundamental das humanidades na formulação de um conhecimento sobre o humano que transcende a visão estritamente científica. Escrevia ele, em 1925, na introdução de um tratado sobre o climatério feminino:

Tal vez se nos reproche el excesivo uso que hacemos de los ejemplos literarios. Lo hacemos así por creerlos tan instructivos como las descripciones de los médicos. El artista recoge sus impresiones directamente de la realidad, sin los prejuicios científicos que restan valor humano a las observaciones médicas. (...) Por ello hemos de acudir a los grandes artistas, que son los psicólogos supremos (...) Hoy podemos estudiar los sentimentos humanos en las comedias de Shakespeare mucho mejor que en el Tratado de las pasiones, de Descartes. No hay que ser el príncipe que todo lo aprendió en los libros, pero tampoco el hombre que lo aprendió todo en la vida. (Gregorio Marañón, 1925: prólogo). ${ }^{5}$

4 Idéia semelhante é desenvolvida também pelo filósofo e educador espanhol Alfonso López Quintás (1994) através do conceito de «âmbito».

5 Marañón costumava afirmar que é entre os artistas e os pensadores, portanto nas humanidades, que vamos encontrar os "especialistas em vida humana» e que os cientistas, médicos e psicólogos, deviam "por necesidad (...) volver de cuando en cuando sus ojos a los "especialistas en vida humana", y estos son, junto a los psicólogos de oficio, y a veces muy sobre ellos, los pensadores y los artistas..." (Apud Laín Entralgo, 1965: p. LI). 
Em sua proposta educacional universitária, Janine Ribeiro defende a idéia de que as humanidades podem "fecundar» as ciências.

Não pensamos que as humanidades constituam simples ilustração embelezada daquilo que, pela via dura, se conclui na pesquisa científica, mas que possam - justamente - formar alunos capazes de questionar em regra as regras que aprenderam, e ser capazes de inovar na pesquisa. (Ribeiro, 1991: p. 17).

Inovar, renovar, ampliar a esfera sensual, afetiva, intelectiva e mesmo volitiva do ser. Interagindo e envolvendo este ser não apenas enquanto ser pensante, mas enquanto ser afetivo, volitivo, ser difuso e indeterminado, as humanidades —a experiência da cultura através das artes, da literatura, da filosofia - possibilitam não só um novo e mais amplo olhar — conhecimento - sobre a realidade, como desencadeiam um processo de profunda transformação no próprio sujeito que olha, que conhece. Em suma, as humanidades apresentam-se como meio privilegiado de humanização do ser, na medida em que amplia as esferas da sua presença, da sua experiência, da sua consciência. As humanidades ajudam-nos a sermos mais humanos.

\section{O LABORATÓRIO DE HUMANIDADES: UMA PROPOSTA EXPERIMENTAL}

Tal postulado, apresentado pelos diversos autores que vimos analisando ao longo deste trabalho vem sendo, neste momento, experimentado na prática no contexto de uma atividade acadêmica desenvolvida pelo Centro de História e Filosofia das Ciências da Saúde (CeHFi) da EPM/UNIFESP intitulada Laboratório de Humanidades (LabHum). Surgido há sete anos, articulada a partir de encontros com estudantes de graduação em medicina, o LabHum apresenta-se hoje como uma ampla experiência universitária que, integrando graduação, pós-graduação e extensão, busca promover a formação humanística e a humanização no âmbito da saúde a partir da leitura e discussão de obras clássicas da literatura universal. Objeto de estudo empírico do projeto regular de pesquisa «As Patologias da Modernidade e os Remédios das Humanidades: investigação e experimentação", o Laboratório de Humanidades aponta para a pertinência de uma experiência heterodoxa promissora no contexto das propostas de humanização em saúde.

Esperamos que em breve possamos apresentar de forma mais ampla e profunda os resultados desta pesquisa que, mesmo numa etapa ainda inicial, já parece confirmar a os postulados esboçados de forma preliminar neste artigo a partir dos referenciais teóricos que fundamentam nosso projeto de pesquisa. 


\section{REFERÊNCIAS BIBLIOGRÁFICAS}

Brasil, Ministério da Educação, Secretaria de Educação Superior (2001): Diretrizes Curriculares para os Cursos de Graduação, Brasília, MEC.

Brasil, Ministério da Saúde (2003): Humaniza SUS: Política Nacional de Humanização, Brasília, Ministério da Saúde.

Cassirer, E. (1956): The Renaissance Philosophy of Man, Chicago, The University of Chicago Press.

Ceccim, R. B.; Merhy, E. E. (2009): «Um agir micropolítico e pedagógico intenso: a humanização entre laços e perspectivas", Interface-Comunic., Saúde, Educ., v.13, s.1: 531-542.

Delumeau, J. (1984): A Civilização do Renascimento, V. II, Lisboa, Estampa.

Deslandes, S. (org.) (2007): Humanização dos Cuidados em Saúde: conceitos, dilemas e práticas, Rio de Janeiro, Ed. Fiocruz.

Esprit, J. (1996): La Fausseté des vertus humaines, Paris, Aubier.

Faye, E. (1998): Philosophie et perfection le l'homme, Paris, JVrin.

Gallian, D. M. C. (2002): "As Humanidades e o Saber Médico», Notandum, Salamanca, v. 9: 47-50.

- (2005): «Por detrás do último ato da ciência-espetáculo: as células-tronco embrionárias", Estudos Avançados, v. 19, n. 55: 253-260.

- (2008): 75X75 EPM/Unifesp: uma história, 75 vidas, São Paulo, Editora da Unifesp.

—; Reginato, V. (2009): "Relação assistencial e sua humanização», in: Ramos, D. L. P. (org.): Bioética, Pessoa eVida, 1 ed. São Caetano do Sul, Difusão Editora, pp. 117-133.

Garin, E. (1989): Idade Média e Renascimento, Lisboa, Editorial Estampa.

Gouhier, H. (1987): L'Anti-humanisme au XVIIème siècle, Paris, JVrin.

Hobsbawm, E. (2005): A Era dos Extremos. O breve século XX, São Paulo, Cia das Letras.

Lain Entralgo, P. (1965): «Vida, obra y persona de Gregorio Marañón», en: Obras Completas de Gregorio Marañón, Vol 1, Madrid.

López Quintás, A. (1994): Cómo formarse en Ética a través de la literatura. Análisis estético de obras literárias, Madrid, Rialp.

Lyotard, J. (1998): A Condição Pós-moderna, Rio de Janeiro: José Olympio, 1998.

Marañón, G. (1925): La edad crítica, Madrid.

Marion, J. L. (1986): Sur le prisme métaphysique de Descartes, Paris, PUF.

Martins, P. H. (2003): Contra a Desumanização da Medicina: críticas sociológicas das práticas médicas modernas, Petrópolis, Vozes.

Nakamoto, P. S. (2008): «A humanização no Pronto Socorro do Hospital das Clínicas da Faculdade de Medicina de Botucatu sob a perspectiva dos profissionais de saúde». Interface-Comunic., Saúde, Educ., v. 12, n. 26: 684-685.

Neves, C. A. B.; Massaro, A. (2009): «Biopolítica, produção de saúde e um outro humanismo", Interface, v. 13, supl. 1: 503-14.

Oakeshott, M. (1991): Racionalism in Politics and Other Essays, Indianápolis, Liberty Fund.

Ortega y Gasset, J. (1999): A Missão da Universidade, Rio de Janeiro, Eduerj.

- (2005): A Desumanização da Arte, $5^{\mathrm{a}}$ ed., São Paulo, Cortez.

Pascal, B. (1963): Pensées, París, Ed. Lafuma, Intégrale/Seui.

-, B. (1991): Écrits sur la grace, en: Oeuvres Complètes, Paris, Ed. Jean Mesnard, DDB.

Passmore, J. (2004): A Perfectibilidade do homem, Rio de Janeiro, Topbooks.

Pico della Mirandola, G. (1956): «Oration on the Dignity of Man», en: Cassirer, E.; Kristeller, P. O.; Randall, J. H. (orgs.): The Renaissance Philosophy of Man, Chicago, The University of Chicago Press. 
Pondé, L. F. (2001): O Homem Insuficiente, São Paulo, Edusp.

Quignard, P. (1996): "Traité sur Esprit», en: Esprit, J.: La Fausseté des Vertus Humaine, París, Aubier.

Renaudet, A. (1945): Autour d'une définition de l'humanisme, Paris, Biblioethèque Française de l'Humanisme, Travaux TVI.

Ribeiro, R. J. (org.) (2001): Humanidades: um novo curso na USP, São Paulo, Edusp.

Sellier, P. (1995): Pascal et Saint Augustin, Paris, Albin Michel.

Souza, L. A. P.; Mendes, V. L. F. (2009): «O conceito de humanização na Política Nacional de Humanização (PNH)", Interface, v. 13, s. 1: 681-688.

Teixeira Coelho, J. A (2001): «Cultura como Experiência», en: Ribeiro, R. J. (org.): Humanidades: um novo curso na USP, São Paulo, Edusp, pp. 65-101.

\section{SOBRE LOS AUTORES}

\section{Dante Marcello Claramonte Gallian}

Historiador, mestre y doctor en Historia Social por la Facultad de Filosofía, Letras y Ciencias Humanas (FFLCH) de la Universidad de São Paulo (USP), Brasil, con postdoctorado por el Centre de Recherches Historiques de la École des Hautes Études en Sciences Sociales (EHESS) de Paris, Francia. Fue profesor de Historia del Arte y de la Cultura en las Universidades Mackenzie (Sao Paulo, Brasil) y Federal de Santa Catarina (Brasil) y profesor visitante en la EHESS de Paris (Francia). Actualmente es profesor y director del Centro de Historia y Filosofia de las Ciencias de la Salud (CeHFi) de la Escola Paulista de Medicina (EPM) de la Universidad Federal de São Paulo (UNIFESP) y Visiting Researcher en el Center of Humanities and Health del King's College London (Inglaterra). Es investigador de FAPESP (Fundación de Ampoyo a la Investigación del Estado de São Paulo) y de CNPq (Consejo Nacional de Investigación de Brasil, desarrollando proyectos de investigación sobre el papel de las humanidades en la formación humanística en Salud y sobre Historia Oral y Narrativas en Salud. Sobre estos temas ha publicado libros y decenas de artículos científicos.

\section{Luiz Felipe Ponde}

Licenciado en Filosofia por la Universidad de São Paulo, mestre y doctor en Historia de la Filosofia por la misma universidad. DEA en Filosofía Contemporánea por la Universidad de Paris VIII y postdoctorado por la Universidad de Tel Aviv. Actualmente es profesor en la Pontificia Universidad Católica de São Paulo y en la Fundación Aramando Alavares Penteado (FAAP-SP). Es también profesor visitante en el CeHFi-EPM-UNIFESP e investigador asociado de FAPESP.

\section{Rafael Ruiz}

Licenciado en Derecho por la Universidad de São Paulo, maestría en Derecho Internacional Público y Doctorado en Historia Social por la misma universidad. Actualmente es profesor adjunto de Historia en la Universidad Federal de São Paulo. Desarrolla el Proyecto "Derechos y Justicia en las Américas", financiado por la FAPESP (Fundação de Amparo à Pesquisa do Estado de São Paulo) y es coordinador del Núcleo de estudios ibéricos de la Universidad Federal de São Paulo. Desde 2007 es también coordenador del Laboratorio de Humanidades de la misma universidad. 